\title{
Intensive weight gain therapy in patients with anorexia nervosa results in improved serum tartrate-resistant acid phosphatase (TRAP) $5 a$ and $5 b$ isoform protein levels
}

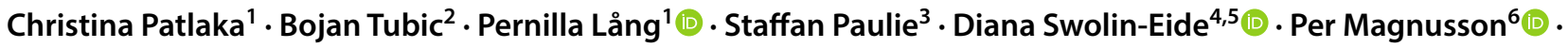 \\ Göran Andersson ${ }^{1}$
}

Received: 30 April 2019 / Accepted: 3 September 2019 / Published online: 17 September 2019

(c) The Author(s) 2019

\begin{abstract}
Aim Tartrate-resistant acid phosphatase (TRAP) exists as isoforms 5a and 5b. TRAP 5a is a biomarker of chronic inflammation and influences adipose tissue and $5 \mathrm{~b}$ associates with bone metabolism/pathologies. The aim was to investigate the association of serum TRAP 5a/5b isoforms with fat and bone markers and anthropometric parameters in patients with anorexia nervosa (AN) during weight gain therapy.

Methods Twenty-five Swedish female AN patients, age 16-24 years, were treated for 12 weeks with a high-energy diet with six meals daily. Serum TRAP 5a/5b, markers of fat/glucose metabolism, markers of bone resorption and formation were measured. Parameters of bone and body composition were assessed by dual-energy X-ray absorptiometry and peripheral quantitative computed tomography.

Results BMI increased from median $15.4 \mathrm{~kg} / \mathrm{m}^{2}$ to $19.0 \mathrm{~kg} / \mathrm{m}^{2}, p<0.0001$. TRAP $5 \mathrm{a}$ and $5 \mathrm{a} / 5 \mathrm{~b}$ ratio increased but TRAP $5 \mathrm{~b}$ decreased during the study. TRAP $\Delta 5 \mathrm{a}$ and $\Delta 5 \mathrm{~b}$ correlated with $\Delta$ insulin and $\Delta$ adiponectin, respectively. TRAP $5 \mathrm{~b}$ correlated with trabecular density at start but not at week 12 . At 12 weeks, TRAP 5 b correlated with CTX, and $\Delta$ decrease in TRAP $5 \mathrm{~b}$ correlated to $\Delta$ increase in bone-specific alkaline phosphatase.

Conclusions This clinical interventional study resulted in increased BMI in patients with AN. The decreased TRAP 5b protein levels confirm a role for TRAP $5 \mathrm{~b}$ as a marker of bone resorption, whereas increased TRAP 5a seemed to derive from systemic changes in bone as well as metabolic changes. The combined detection of TRAP 5a and TRAP 5b in serum could be an indicator of improved bone metabolism.

Level of evidence Level III, prospective interventional cohort study.
\end{abstract}

Keywords Tartrate-resistant acid phosphatase $\cdot$ Acp5 $\cdot$ Anorexia nervosa $\cdot$ Osteoclasts $\cdot$ Bone $\cdot$ Biomarker

\section{Introduction}

Anorexia nervosa (AN) is a severe psychiatric disorder predominantly affecting female adolescents. In most cases, teenagers will gradually recover from the illness, although

Per Magnusson and Göran Andersson shared senior authorship.

Electronic supplementary material The online version of this article (https://doi.org/10.1007/s40519-019-00776-8) contains supplementary material, which is available to authorized users.

Pernilla Lång

pernilla.lang@ki.se

Extended author information available on the last page of the article
AN is known for its severe complications [1]. The prevalence of AN is approximately $1 \%$ among 17 -year-old Swedish girls [2]. Many patients recover after treatment as outpatients, while some patients require hospitalization. A novel intensive nutrition therapy that initially starts with an extreme high caloric intake has recently and successfully been implemented for hospitalized AN patients resulting in significant increase in body mass index (BMI), weight and fat mass [3].

Peak bone mass is mostly acquired during early adulthood, which makes youth the best time to invest in bone health [4]. Reduced bone mineral density (BMD) is a common finding in patients with $\mathrm{AN}$, which is a sign of impaired bone health [5]. AN treatments, such as intensive nutrition therapy, increase BMD, bone mineral content (BMC) and 
biochemical parameters for bone formation such as bonespecific alkaline phosphatase (BALP) and osteocalcin [6]. However, restoring bone health in AN patients is a slow process [7] resulting in long-term increased fracture risk [8, 9].

Tartrate-resistant acid phosphatase (TRAP; EC 3.1.3.2; Acp5; TRAcP) is a novel marker of adipose tissue regulation as well as a classical marker of osteoclasts and bone resorption. TRAP consists of two isoforms, TRAP 5a and TRAP 5b, which differ in structure, phosphatase activity [10], localization and most importantly biomarker potential [11]. TRAP 5a has been shown to be associated with inflammatory conditions such as obesity [12], overweight [13, 14], sarcoidosis [15] and rheumatoid arthritis [16, 17]. Conversely, TRAP $5 b$ has been used as a marker of bone resorption [18, 19], chronic kidney disease [20], coronary atherosclerosis [21] and has been proposed as a marker of bone cancer metastasis [22]. With regard to AN patients, only TRAP $5 \mathrm{~b}$ has been studied with mixed results. TRAP 5b was reportedly upregulated in one study [23] but unchanged in another investigation [24].

The TRAP isoforms $5 \mathrm{a}$ and $5 \mathrm{~b}$ have previously been shown to be associated with mechanisms regulating both adipose tissue and bone remodeling. Since both systems are involved in the pathophysiology of AN, this study was designed to elucidate if the circulating levels of TRAP 5a and/or $5 b$ could contribute with further information regarding the cellular response, in adipose tissue and/or bone remodeling, to weight gain therapy in young female patients with AN.

\section{Methods}

\section{Study population}

The present study took place between January 2012 and July 2014 and patients were adolescents with severe AN admitted to the Queen Silvia Children's Hospital, Göteborg, Sweden. Patients fulfilling inclusion criteria were offered the 12 week treatment aiming to restore body weight and normalize eating behavior via a structured behavioral program [3]. Twenty-five female participants, age 16-24 years, fulfilled inclusion criteria being diagnosed with AN according to the Diagnostic and Statistical Manual of Mental Disorders IV [25]. Exclusion criteria included diabetes mellitus, inflammatory bowel disease, or life-threatening physical conditions demanding care at internal medicine department. The study was approved by the regional research ethics committee at the University of Gothenburg 720-11. Informed consent and assent were obtained from all study participants and in cases of minor subjects $(<18$ years of age) also from their parents. Of the 25 patients, 2 discontinued the study because they did not want to participate in the 12-week program and one because diagnosis was reconsidered and, thus, the final number of subjects included in the current study was 22 (Supplementary Fig. 1).

\section{Study design}

Study design was as described by Pettersson et al. [3] Energy and nutrient intake was planned, served and supervised for all patients during 12 weeks and $24 \mathrm{~h}$ per day. Patients underwent nutritional rehabilitation for 12 weeks, with an extra high-energy diet, starting at median $75 \mathrm{kcal} /$ $\mathrm{kg} /$ day and gradually declining to $48 \mathrm{kcal} / \mathrm{kg} /$ day during the study [3]. In addition, from day two, all patients were served $3 \times 200 \mathrm{ml}$ of high-energy liquid nutritional supplements $(1.5 \mathrm{kcal} / \mathrm{ml})$ together with snacks and night meal. As the patients gained weight, liquid supplements were removed from the menu. The mean nutrient intakes at week 1 and 12 were: protein $17 \mathrm{E} \%$ and $17 \mathrm{E} \%$; fat $34 \mathrm{E} \%$ and $33 \mathrm{E} \%$; and carbohydrate $48 \mathrm{E} \%$ and $48 \mathrm{E} \%$, respectively. Subjects increased in median $9.9 \mathrm{~kg}(5.5-17.0 \mathrm{~kg})$ during the study.

\section{Measurement of physiological and biochemical parameters}

Measurement of physiological and biochemical parameters, baseline cohort characteristics and biochemical parameters at start and 12 weeks were performed as reported elsewhere $[3,6]$.

\section{Assessment of BMD and body composition}

Fat mass, lean body mass as well as BMD and BMC were measured with dual-energy X-ray absorptiometry (DXA; Lunar Prodigy, GE Lunar Corp., Madison, WI) for total body (TB), lumbar spine (L1-L4), left arm and left leg. The peripheral quantitative computed tomography (pQCT) measurements were performed on the left tibia at $4 \%$ and $66 \%$ of the tibia length using an XCT 2000 (Stratec Medizintechnik $\mathrm{GmbH}$, Pforzheim, Germany) with software version 6.00 as reported elsewhere [26]. The left calcaneal BMD and BMC were measured using DXA and laser (DXL) Calscan technique (Demetech AB, Solna, Sweden), where the measurement by DXA is combined with a laser measurement of the total calcaneal thickness [27]. All DXA, DXL and pQCT measurements were done by the same staff as previously reported [3].

\section{Serum pre-treatment for ELISA and standard curve dilution of recombinant TRAP}

Samples were pre-treated in 1 volume $1 \mathrm{M}$ glycine $\mathrm{pH} 2.3$ at $37{ }^{\circ} \mathrm{C}$ for $1 \mathrm{~h}$ and then 1 volume of $1 \mathrm{M}$ Tris- $\mathrm{HCl}, \mathrm{pH}$ 8.3 was added. Samples were then diluted 1:1 in ELISA 
diluent buffer (Mabtech AB, Nacka, Sweden). Recombinant TRAP 5a standards were diluted in $1 \mathrm{M}$ glycine $\mathrm{pH} 2.3,1 \mathrm{M}$ Tris- $\mathrm{HCl}, \mathrm{pH} 8.3$, and then in ELISA diluent buffer, ratio $1: 1: 4$.

\section{Monoclonal antibody (mAb) and TRAP 5a separation from TRAP 5b}

The mouse monoclonal antibody 46 (Mabtech) recognizes TRAP 5a [12] and, thus, plates coated with mAb 46 were used for quantifying and clearing of TRAP $5 \mathrm{a}$ in serum samples. MAb 25.44 (Mabtech) recognizes both TRAP 5a and TRAP 5b; thus, it was used after pre-incubation of samples with $\mathrm{mAb} 46$ to capture and quantify the remaining fraction of TRAP that should only contain TRAP 5b.

\section{TRAP 5a and TRAP 5b sandwich ELISA}

For capturing of TRAP 5a, samples and recombinant TRAP 5a standards were incubated at $4{ }^{\circ} \mathrm{C}$ overnight in 96-well half-volume ELISA plates (Costar, Chicago, IL) and coated with $5 \mu \mathrm{g} / \mathrm{ml} \mathrm{mAb} 46$ at $4{ }^{\circ} \mathrm{C}$ overnight. The samples, depleted of TRAP 5a, were thereafter transferred to 96-well half-volume ELISA plates (Costar) and coated with $5 \mu \mathrm{g} /$ $\mathrm{ml} \mathrm{mAb} 25.44$ at $4{ }^{\circ} \mathrm{C}$ overnight, for capturing of TRAP 5 b. Recombinant TRAP 5a standards $(0-4 \mathrm{ng} / \mathrm{ml})$ were additionally added to the $\mathrm{mAb} 25.44$ plate. After incubation for $2 \mathrm{~h}$ at room temperature, plates were washed 3 times in TBST (25 mM Tris pH 7.6, $150 \mathrm{mM} \mathrm{NaCl}, 0.1 \%$ Tween 20) followed by incubation with $0.25 \mu \mathrm{g} / \mathrm{ml}$ biotinylated detection $\mathrm{mAb} 12.56$ for $1 \mathrm{~h}$ at room temperature. After washing three times in TBST, plates were incubated with streptavidin-horseradish-peroxidase (Mabtech) 1:1000 for $30 \mathrm{~min}$ and washed 3 times in TBST. Finally, plates were developed using K-Blue Substrate (TMB; Neogen, Lansing, MI) for 20 min and stopped using $50 \mu \mathrm{l} 1 \mathrm{M} \mathrm{H}_{2} \mathrm{SO}_{4}$ after which absorbance was measured at $450 \mathrm{~nm}$ in BioTek's PowerWave HT microplate spectrophotometer (BioTek, Winooski, VT). Quantification of TRAP 5a was done using the TRAP 5 a standard curve on the mAb 46-coated plate. Quantification of TRAP $5 \mathrm{~b}$ was done using the newly added TRAP $5 \mathrm{a}$ standards and the samples depleted of TRAP 5a on the plate coated with $\mathrm{mAb} 25.44$. The transferred standards of TRAP $5 \mathrm{a}$ from $\mathrm{mAb} 46$ to $\mathrm{mAb} 25.44$ plate were used to correct for any potential carryover of TRAP 5 a from plate mAb 46 to plate $\mathrm{mAb} 25.44$.

\section{Statistical analysis}

For the analysis of TRAP 5a and TRAP 5b before and after 12 weeks, samples were compared using Wilcoxon signedrank test. Correlation analysis of TRAP 5a and TRAP $5 b$ to physiological and biochemical parameters was performed using Spearman's rank correlation as not all parameters were normally distributed as evaluated with Shapiro-Wilk normality test. A $p$ value of $<0.05$ was considered statistically significant for all analyses. All statistical analysis was performed using the GraphPad Prism 6 software (GraphPad Software, Inc., La Jolla, CA).

\section{Results}

\section{Serum TRAP $5 a$ and TRAP $5 b$ are changed in opposite directions after weight gain therapy}

The initial weight of the subjects was in median (minimum-maximum) $44.3 \mathrm{~kg}(36.3-50.6 \mathrm{~kg})$, which increased to $54.3 \mathrm{~kg}$ (44.0-61.4), $p<0.0001$, at week 12. Subjects gained in median $9.9 \mathrm{~kg}(5.5-17.0 \mathrm{~kg})$ during the study period ( $22 \%$ of initial weight). BMI increased from median $15.4 \mathrm{~kg} / \mathrm{m}^{2}\left(13.4-17.3 \mathrm{~kg} / \mathrm{m}^{2}\right)$ to $19.0 \mathrm{~kg} / \mathrm{m}^{2}(16.2-20.6 \mathrm{~kg} /$ $\left.\mathrm{m}^{2}\right), p<0.0001$. Fat mass percentage, measured by DXA, increased from median (minimum-maximum) $11.4 \%$ (4.4-24.8\%) to $26.7 \%$ (16.9-39.8\%), $p<0.0001$ [28].

At the study start, serum TRAP 5a levels were 1.6 (0.35-3.21) ng/ml [median (minimum-maximum)], while after 12 weeks of intensive weight gain therapy, TRAP 5 a levels increased significantly to $2.4(0.78-3.75) \mathrm{ng} /$ $\mathrm{ml}, p=0.0002$ (Fig. 1a). On the contrary, serum TRAP $5 \mathrm{~b}$ decreased from $1.85(0.31-4.37) \mathrm{ng} / \mathrm{ml}$ at the study start to $0.82(0.03-2.87) \mathrm{ng} / \mathrm{ml}, p<0.0001$, after 12 weeks (Fig. 1b). The TRAP 5a/TRAP 5b ratio increased significantly from $0.71(0.39-2.20)$ at the study start to 3.02 (1.12-31.42) at week 12, $p<0.0001$ (Fig. 1c). Total TRAP levels (TRAP $5 \mathrm{a}$ and $5 \mathrm{~b}$ ) did not change significantly over the study period, $p=0.08$ (Fig. 1d); total TRAP levels atstudy start were $3.71(0.90-6.56) \mathrm{ng} / \mathrm{ml}$ and $3.25(0.79-6.38)$ $\mathrm{ng} / \mathrm{ml}$ on week 12 .

At the study start, correlation analysis demonstrated that serum TRAP 5a had a tendency for a positive correlation with serum TRAP 5b $(R=0.40, p=0.07)$ and at week 12 there was a positive correlation between TRAP $5 \mathrm{a}$ and $5 \mathrm{~b}$ $(R=0.49, p=0.02)$ (Fig. 1e). No association was observed between the delta ( $\Delta$, change between weeks 1 and 12) values for TRAP $5 \mathrm{a}$ and $5 \mathrm{~b}$ (Fig. 1f).

\section{TRAP 5a and TRAP 5b, as well as changes in their levels, do not correlate to weight anthropometric parameters [29]}

At start, serum TRAP 5a correlated negatively to weight $(R=-0.49, p=0.02$ (Table 1; Fig. 2a). However, serum TRAP 5a and TRAP 5b did not correlate with most of the investigated parameters (BMI, total fat mass, and total lean mass; Table 1). Additionally, changes in biochemical 

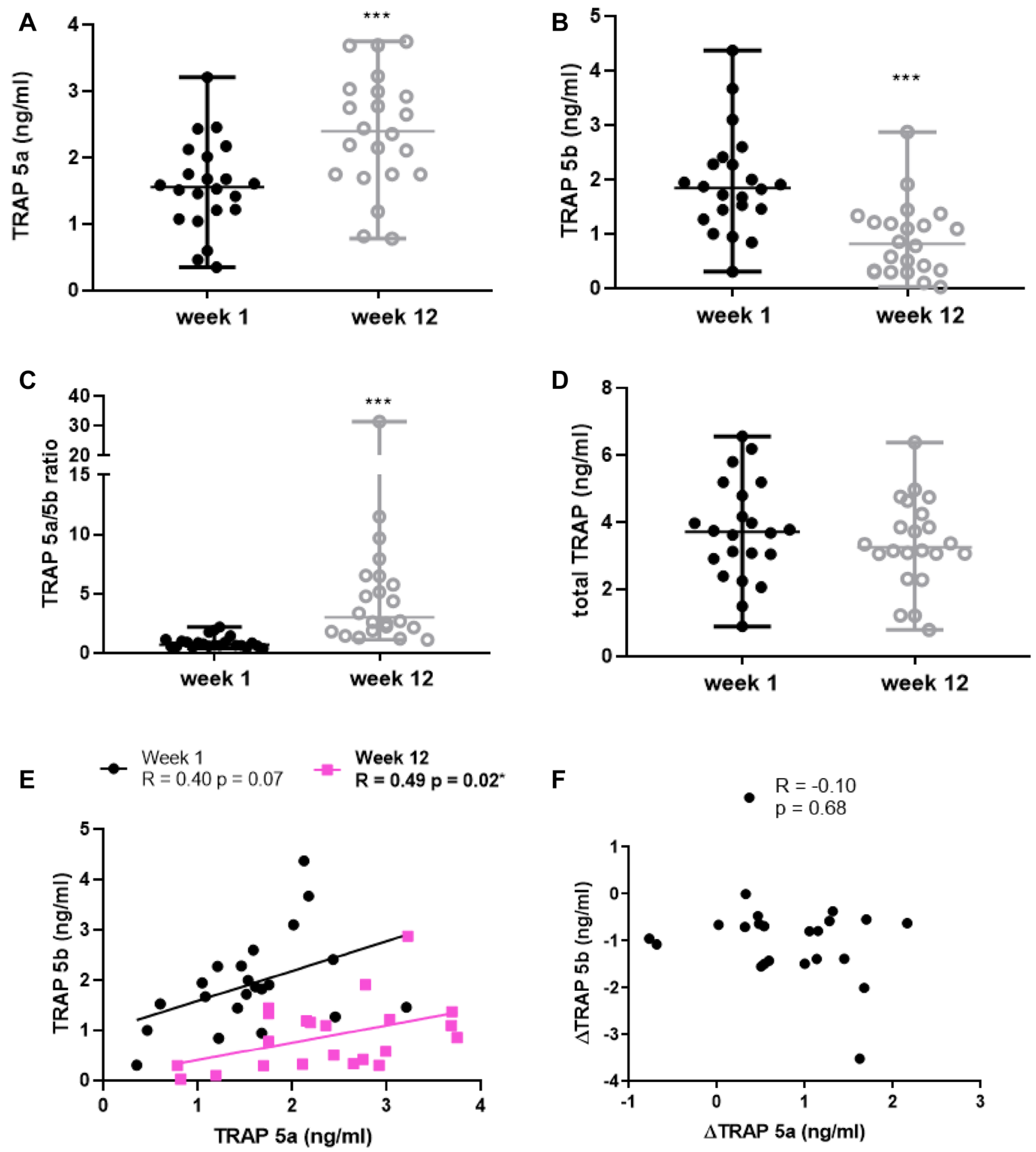

Fig. 1 TRAP isoform profile in anorexia nervosa patients during intensive weight gain therapy. a Serum TRAP 5a protein. b Serum TRAP $5 b$ protein. c Ratio of TRAP $5 \mathrm{a} / 5 \mathrm{~b}$ protein. d Serum total TRAP (TRAP $5 \mathrm{a}$ and $5 \mathrm{~b}$ ) protein. e Correlation of TRAP 5a

and $5 \mathrm{~b}$ protein weeks 1 and 12 . f Correlation of $\triangle$ TRAP (weeks $12-$ week 1) $5 \mathrm{a}$ and $\Delta 5 \mathrm{~b} . N=22$ in all analysis. Values are shown as median \pm range in all analysis. $* * * p<0.001$

parameters related to metabolism, i.e., insulin, correlated to the observed changes in TRAP $5 \mathrm{a}$ and TRAP $5 \mathrm{a} / 5 \mathrm{~b}$, respectively, i.e., $\Delta$ insulin to $\Delta$ TRAP 5a; $R=0.54, p=0.01$; TRAP

$5 \mathrm{a} / 5 \mathrm{~b}$ to insulin at week $1 ; R=0.56, p=0.01$, respectively (Table 1, Fig. 2b, c). 
Table 1 Correlations of TRAP isoforms to weight and adipose tissue metabolism parameters

\begin{tabular}{|c|c|c|c|c|c|c|c|}
\hline & \multirow[t]{2}{*}{ TRAP isoform } & \multicolumn{2}{|l|}{ Week 1} & \multicolumn{2}{|c|}{ Week 12} & \multicolumn{2}{|l|}{ Delta } \\
\hline & & $p$ value & $R$ value & $p$ value & $R$ value & $p$ value & $R$ value \\
\hline Weight (kg) & $5 \mathrm{a}$ & $0.02 *$ & -0.49 & 0.19 & -0.29 & 0.64 & 0.11 \\
\hline BMI $\left(\mathrm{kg} / \mathrm{m}^{2}\right)$ & $5 \mathrm{a}$ & 0.21 & -0.28 & 0.95 & -0.01 & 0.77 & 0.07 \\
\hline Total fat mass $(\%)$ & $5 a$ & 0.53 & -0.14 & 0.12 & -0.34 & 0.76 & 0.07 \\
\hline Fat mass $(\mathrm{g})$ & $5 a$ & 0.43 & -0.18 & 0.31 & -0.23 & 0.95 & 0.02 \\
\hline Total lean mass (g) & $5 \mathrm{a}$ & 0.09 & -0.37 & 0.89 & 0.03 & 0.54 & -0.11 \\
\hline Total adiponectin $(\mathrm{mg} / \mathrm{L})$ & $5 \mathrm{a}$ & 0.97 & -0.01 & 0.46 & 0.17 & 0.37 & 0.20 \\
\hline Insulin mU/L) & $5 a$ & 0.53 & 0.14 & 0.93 & 0.02 & $0.01 * *$ & 0.54 \\
\hline Weight (kg) & $5 b$ & 0.58 & -0.13 & 0.25 & -0.26 & 0.97 & 0.01 \\
\hline BMI $\left(\mathrm{kg} / \mathrm{m}^{2}\right)$ & $5 b$ & 0.51 & 0.15 & 0.93 & 0.02 & 0.85 & -0.04 \\
\hline Total fat mass (\%) & $5 b$ & 0.50 & -0.15 & 0.97 & 0.01 & 0.92 & -0.02 \\
\hline Fat mass $(\mathrm{g})$ & $5 b$ & 0.47 & -0.16 & 0.92 & -0.02 & 0.82 & 0.05 \\
\hline Total lean mass (g) & $5 b$ & 0.74 & 0.08 & 0.77 & -0.07 & 0.97 & 0.01 \\
\hline Total adiponectin $(\mathrm{mg} / \mathrm{L})$ & $5 b$ & 0.19 & -0.29 & 0.85 & -0.04 & 0.06 & -0.41 \\
\hline Insulin (mU/L) & $5 b$ & 0.11 & -0.35 & 0.79 & -0.06 & 0.21 & -0.28 \\
\hline Weight (kg) & $5 a / 5 b$ & 0.25 & -0.26 & 0.41 & 0.19 & 0.53 & 0.14 \\
\hline BMI $\left(\mathrm{kg} / \mathrm{m}^{2}\right)$ & $5 a / 5 b$ & 0.54 & -0.14 & 0.67 & 0.10 & 0.61 & 0.12 \\
\hline Total fat mass (\%) & $5 a / 5 b$ & 0.41 & 0.19 & 0.89 & -0.03 & 0.15 & 0.32 \\
\hline Fat mass $(\mathrm{g})$ & $5 a / 5 b$ & 0.41 & 0.19 & 0.95 & 0.02 & 0.14 & 0.33 \\
\hline Total lean mass (g) & $5 \mathrm{a} / 5 \mathrm{~b}$ & 0.08 & -0.38 & 0.67 & 0.10 & 0.51 & 0.15 \\
\hline Total adiponectin $(\mathrm{mg} / \mathrm{L})$ & $5 \mathrm{a} / 5 \mathrm{~b}$ & 0.06 & 0.41 & 0.66 & 0.10 & 0.75 & 0.07 \\
\hline Insulin mU/L) & $5 a / 5 b$ & $\mathbf{0 . 0 1} * *$ & 0.56 & 0.32 & 0.22 & 0.30 & 0.23 \\
\hline
\end{tabular}

Absolute values for adipose tissue metabolism parameters can be found in [28, 29] (previously published parameters) and in Supplementary Table I É(previously unpublished parameters)

Bold values indicate that are statistically significant. All analysis $n=22$. $* p<0.05, * * p<0.01$

\section{TRAP 5a, TRAP $5 b$ and TRAP 5a/5b and their changes correlate to bone parameters}

TRAP 5a correlated inversely to lumbar spine (L1-L4) BMD at week 12 , but not at the study start; $R=-0.45$, $p=0.03 ; R=-0.35, p=0.11$, respectively (Table 2, Fig. 3a). $\Delta$ lumbar spine (L1-L4) BMC was negatively correlated to $\Delta$ TRAP 5a $(R=-0.49, p=0.02)$ and had a tendency for inverse correlation both at week 1 and week $12(R=-0.41$, $p=0.06 ; R=-0.42, p=0.05$, respectively). TRAP $5 \mathrm{~b}$ at week 1 correlated to calcaneal BMD and trabecular density measured by pQCT $(R=-0.46, p=0.03 ; R=-0.54$, $p=0.01$, respectively). At week 12 , TRAP $5 \mathrm{~b}$ correlated positively to cortical density (Fig. $3 \mathrm{~b}, R=-0.47, p=0.03$ ). Changes in trabecular density were positively correlated to changes in TRAP $5 \mathrm{~b}(R=0.50, p=0.02)$.

TRAP $5 \mathrm{a} / 5 \mathrm{~b}$ correlated to total BMC $(R=-0.43$, $p=0.05)$, calcaneal BMD $(R=-0.50, p=0.02)$, calcaneal BMC $(R=-0.58, p=0.004)$, cortical density $(\mathrm{R}=0.53, \mathrm{p}=$ $0.01)$ and trabecular density $(R=-0.45, p=0.04)$ (Table 2$)$.

TRAP 5a and TRAP 5b were analyzed for correlation to the bone formation marker BALP and the bone resorption marker CTX. Serum TRAP 5a levels were not correlated to the above-mentioned parameters (Table 2). TRAP 5 b showed a tendency for correlation with carboxy-terminal cross-linking telopeptide of type I collagen (CTX) at the study start and correlated positively at week $12(R=0.41, p=0.06$; (Fig. 3c) $R=0.56, p=0.01$, respectively). TRAP $5 \mathrm{a} / 5 \mathrm{~b}$ correlated negatively to CTX at both week $1(R=-0.60$, $p=0.003)$ and week $12(R=-0.57, p=0.02)$. Moreover, TRAP $5 \mathrm{~b}$ changes correlated positively to changes in BALP ( $\triangle$ TRAP $5 \mathrm{~b}$ versus $\triangle$ BALP, (Fig. $3 \mathrm{~d}$ ) $R=0.52, p=0.01$ ).

\section{Discussion}

In this prospective interventional study, we investigated changes in the circulating levels of TRAP 5a and TRAP $5 \mathrm{~b}$ derived from patients with severe AN during rapid weight gain therapy for 12 weeks. Markers of bone turnover, including TRAP $5 b$, have previously been studied and assessed for their potential to predict the uncoupling of bone formation and resorption in patients with AN [23, 24]. The present study constitutes, to our knowledge, the first effort to address changes in both serum TRAP 5a and TRAP 5b during large metabolic changes over short period of time in patients that initially are in a late stage of severe $\mathrm{AN}$ and return to a more normalized BMI. Moreover, this 
A
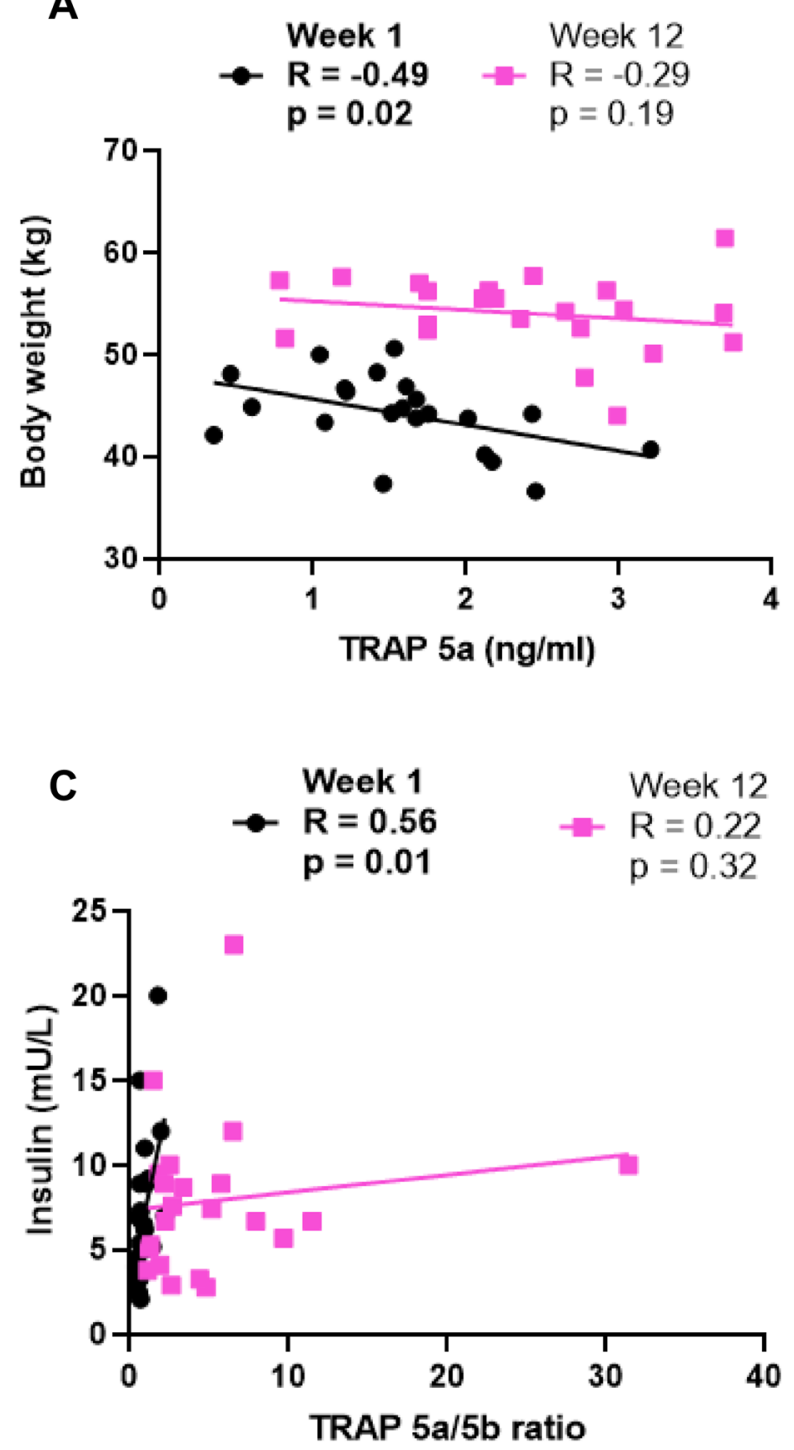

B
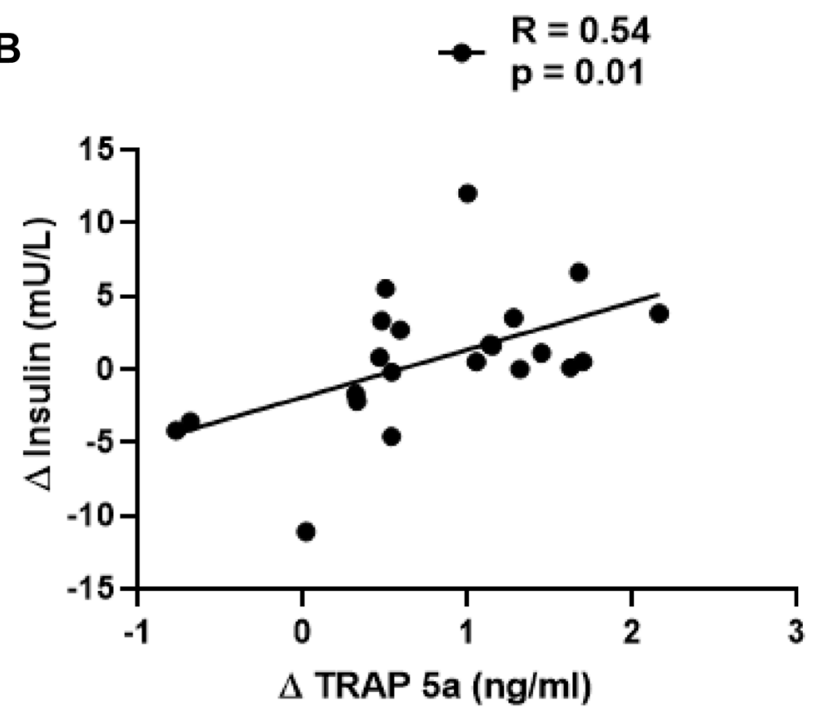

Fig. 2 Correlations of TRAP isoforms to weight and insulin. a Serum TRAP 5a protein vs body weight. b Serum $\Delta$ TRAP 5 a vs $\Delta$ insulin. c Serum TRAP $5 \mathrm{a} / 5 \mathrm{~b}$ ratio vs insulin. $N=22$ in all analysis

is also the first study to investigate the potential use of TRAP $5 \mathrm{a}$ and TRAP $5 \mathrm{~b}$, and the $5 \mathrm{a} / 5 \mathrm{~b}$ ratio, as markers to reflect restoration of bone remodeling in patients with AN during nutritional therapy resulting in a weight increase mainly due to substantial net gain in fat mass. Patients were served six meals daily according to the described nutritional plan, which resulted in a large change in body composition. Fat mass percentage was highly increased from 11.4 to $26.7 \%$, demonstrating that the BMI increase was mainly due to increased fat mass and not lean mass. Hence, this therapy provides a possible clinical model to study changes of the different forms of TRAP within a rather short period of time during large changes in energy metabolism.
Serum TRAP 5a was upregulated after 12 weeks and has previously been shown to be associated with adipose parameters [12, 30] and bone tissue [31]. Serum TRAP 5a reached levels that were in the same magnitude that has been reported for healthy individuals [32], which also is in concurrence with bone and weight assessments reaching a near-healthy state [3]. The lack of association between TRAP 5a or TRAP 5a/5b and anthropometric fat parameters, e.g., BMI, fat mass and fat content does, however, not support a role for TRAP 5a in expansion of the adipose tissue in this particular situation, in contrast to the development of obesity [12]. A major contributor may be related to whether the accumulation of adipose tissue occurs as a result of going from underweight to normal as in this cohort 
Table 2 Correlations of TRAP isoforms to bone mass and biochemical parameters

\begin{tabular}{|c|c|c|c|c|c|c|c|}
\hline & \multirow[t]{2}{*}{ TRAP isoform } & \multicolumn{2}{|l|}{ Week 1} & \multicolumn{2}{|l|}{ Week 12} & \multicolumn{2}{|l|}{ Delta } \\
\hline & & $p$ value & $R$ value & $p$ value & $R$ value & $p$ value & $R$ value \\
\hline Total BMD $\left(\mathrm{g} / \mathrm{cm}^{2}\right)$ & $5 \mathrm{a}$ & 0.56 & -0.13 & 0.19 & -0.27 & 0.92 & 0.02 \\
\hline Total BMC (g) & $5 \mathrm{a}$ & 0.17 & -0.30 & 0.40 & -0.19 & 0.50 & -0.15 \\
\hline Spine BMD (L1-L4) $\left(\mathrm{g} / \mathrm{cm}^{2}\right)$ & $5 \mathrm{a}$ & 0.11 & -0.35 & $0.03 *$ & -0.45 & 0.06 & -0.40 \\
\hline Spine BMC (L1-L4) (g) & $5 \mathrm{a}$ & 0.06 & -0.41 & 0.05 & -0.42 & $0.02 *$ & -0.49 \\
\hline Calcaneal BMD $\left(\mathrm{g} / \mathrm{cm}^{2}\right)$ & $5 a$ & 0.84 & -0.05 & 0.93 & 0.02 & 0.88 & -0.03 \\
\hline Calcaneal BMC (g) & $5 \mathrm{a}$ & 0.47 & -0.16 & 0.44 & -0.18 & 0.47 & -0.16 \\
\hline pQCT cortical density $\left(\mathrm{mg} / \mathrm{cm}^{3}\right)$ & $5 \mathrm{a}$ & 0.92 & -0.02 & 0.35 & -0.21 & 0.34 & 0.21 \\
\hline pQCT trabecular density $\left(\mathrm{mg} / \mathrm{cm}^{3}\right)$ & $5 \mathrm{a}$ & 0.73 & -0.08 & 0.31 & -0.23 & 0.07 & -0.39 \\
\hline $\operatorname{BALP}(\mu \mathrm{g} / \mathrm{L})$ & $5 \mathrm{a}$ & 0.35 & 0.21 & 0.73 & 0.08 & 0.33 & 0.22 \\
\hline CTX (ng/ml) & $5 \mathrm{a}$ & 0.92 & -0.02 & 0.57 & 0.13 & 0.43 & 0.18 \\
\hline Total osteocalcin (ng/mL) & $5 \mathrm{a}$ & 0.63 & 0.11 & 0.74 & 0.08 & 0.12 & 0.34 \\
\hline Undercarboxylated osteocalcin (ng/mL) & $5 \mathrm{a}$ & 0.39 & 0.19 & 0.77 & 0.07 & 0.14 & 0.32 \\
\hline Carboxylated osteocalcin (ng/mL) & $5 \mathrm{a}$ & 0.38 & -0.20 & 0.91 & 0.02 & 0.97 & -0.00 \\
\hline $25 \mathrm{OH}$ vitamin $\mathrm{D}(\mathrm{nmol} / \mathrm{L})$ & $5 \mathrm{a}$ & 0.73 & 0.08 & 0.81 & 0.06 & 0.31 & 0.23 \\
\hline Total BMD $\left(\mathrm{g} / \mathrm{cm}^{2}\right)$ & $5 b$ & 0.38 & 0.20 & 0.45 & -0.17 & 0.30 & 0.23 \\
\hline Total BMC (g) & $5 b$ & 0.34 & 0.21 & 0.57 & -0.13 & 0.46 & 0.17 \\
\hline Spine BMD (L1-L4) $\left(\mathrm{g} / \mathrm{cm}^{2}\right)$ & $5 b$ & 0.80 & 0.06 & 0.13 & -0.33 & 0.97 & 0.01 \\
\hline Spine BMC (L1-L4) (g) & $5 b$ & 0.99 & -0.00 & 0.05 & -0.42 & 0.42 & 0.18 \\
\hline Calcaneal BMD (g/cm²) & $5 \mathrm{~b}$ & $\mathbf{0 . 0 3} *$ & 0.46 & 0.14 & 0.32 & 0.14 & 0.32 \\
\hline Calcaneal BMC (g) & $5 \mathrm{~b}$ & 0.09 & 0.37 & 0.77 & 0.07 & $0.04 *$ & 0.44 \\
\hline pQCT cortical density $\left(\mathrm{mg} / \mathrm{cm}^{3}\right)$ & $5 b$ & 0.06 & -0.41 & $0.03 *$ & -0.47 & 0.19 & 0.29 \\
\hline pQCT trabecular density $\left(\mathrm{mg} / \mathrm{cm}^{3}\right)$ & $5 b$ & $0.009 * *$ & 0.54 & 0.54 & 0.14 & $0.02 *$ & 0.50 \\
\hline $\operatorname{BALP}(\mu \mathrm{g} / \mathrm{L})$ & $5 b$ & 0.93 & -0.02 & 0.19 & 0.29 & $0.01 *$ & 0.52 \\
\hline CTX (ng/mL) & $5 b$ & 0.06 & 0.41 & $0.007 * *$ & 0.56 & 0.18 & 0.30 \\
\hline Total osteocalcin (ng/mL) & $5 b$ & 0.58 & 0.13 & 0.06 & 0.41 & 0.19 & 0.29 \\
\hline Undercarboxylated osteocalcin (ng/mL) & $5 b$ & 0.94 & 0.02 & 0.16 & 0.31 & 0.53 & -0.14 \\
\hline Carboxylated osteocalcin (ng/mL) & $5 b$ & 0.71 & 0.08 & 0.60 & 0.12 & 0.28 & 0.24 \\
\hline $25 \mathrm{OH}$ vitamin $\mathrm{D}(\mathrm{nmol} / \mathrm{L})$ & $5 b$ & 0.73 & -0.08 & 0.76 & -0.07 & 0.47 & -0.16 \\
\hline Total BMD (g/cm²) & $5 a / 5 b$ & 0.32 & -0.22 & 0.50 & 0.15 & 0.29 & 0.24 \\
\hline Total BMC (g) & $5 \mathrm{a} / 5 \mathrm{~b}$ & $\mathbf{0 . 0 5 *}$ & -0.43 & 0.64 & 0.11 & 0.51 & 0.15 \\
\hline Spine BMD (L1-L4) $\left(\mathrm{g} / \mathrm{cm}^{2}\right)$ & $5 a / 5 b$ & 0.28 & -0.24 & 0.21 & 0.28 & 0.87 & -0.04 \\
\hline Spine BMC (L1-L4) (g) & $5 a / 5 b$ & 0.20 & -0.28 & 0.13 & 0.34 & 0.70 & -0.09 \\
\hline Calcaneal BMD (g/cm²) & $5 a / 5 b$ & $0.02 *$ & -0.50 & 0.06 & -0.41 & 0.26 & 0.25 \\
\hline Calcaneal BMC (g) & $5 \mathrm{a} / 5 \mathrm{~b}$ & $0.004 * *$ & -0.58 & 0.30 & -0.23 & 0.36 & 0.20 \\
\hline pQCT cortical density $\left(\mathrm{mg} / \mathrm{cm}^{3}\right)$ & $5 a / 5 b$ & $0.01 * *$ & 0.53 & $0.03 *$ & 0.47 & 0.45 & 0.17 \\
\hline pQCT trabecular density $\left(\mathrm{mg} / \mathrm{cm}^{3}\right)$ & $5 \mathrm{a} / 5 \mathrm{~b}$ & $\mathbf{0 . 0 4} *$ & -0.45 & 0.37 & -0.20 & 1.00 & -0.00 \\
\hline BALP $(\mu \mathrm{g} / \mathrm{L})$ & $5 a / 5 b$ & 0.20 & 0.28 & 0.30 & -0.23 & 0.50 & -0.15 \\
\hline CTX (ng/mL) & $5 \mathrm{a} / 5 \mathrm{~b}$ & $\mathbf{0 . 0 0 3} * *$ & -0.60 & $\mathbf{0 . 0 1} * *$ & -0.57 & 0.06 & -0.41 \\
\hline Total osteocalcin (ng/mL) & $5 a / 5 b$ & 0.71 & 0.09 & 0.10 & -0.36 & 0.14 & -0.33 \\
\hline Undercarboxylated osteocalcin (ng/mL) & $5 \mathrm{a} / 5 \mathrm{~b}$ & 0.10 & 0.36 & 0.46 & -0.17 & 0.53 & -0.14 \\
\hline Carboxylated osteocalcin (ng/mL) & $5 a / 5 b$ & 0.58 & -0.12 & 0.95 & -0.13 & 0.92 & 0.02 \\
\hline $25 \mathrm{OH}$ vitamin $\mathrm{D}(\mathrm{nmol} / \mathrm{L})$ & $5 \mathrm{a} / 5 \mathrm{~b}$ & 0.76 & 0.07 & 0.79 & -0.06 & 0.40 & 0.19 \\
\hline
\end{tabular}

Absolute values for bone mass and biochemical parameters can be found in [28, 29] (previously published parameters) and in Supplementary Table I (previously unpublished parameters)

Bold values indicate that are statistically significant. All analysis $n=22 . * p<0.05, * * p<0.01$ 

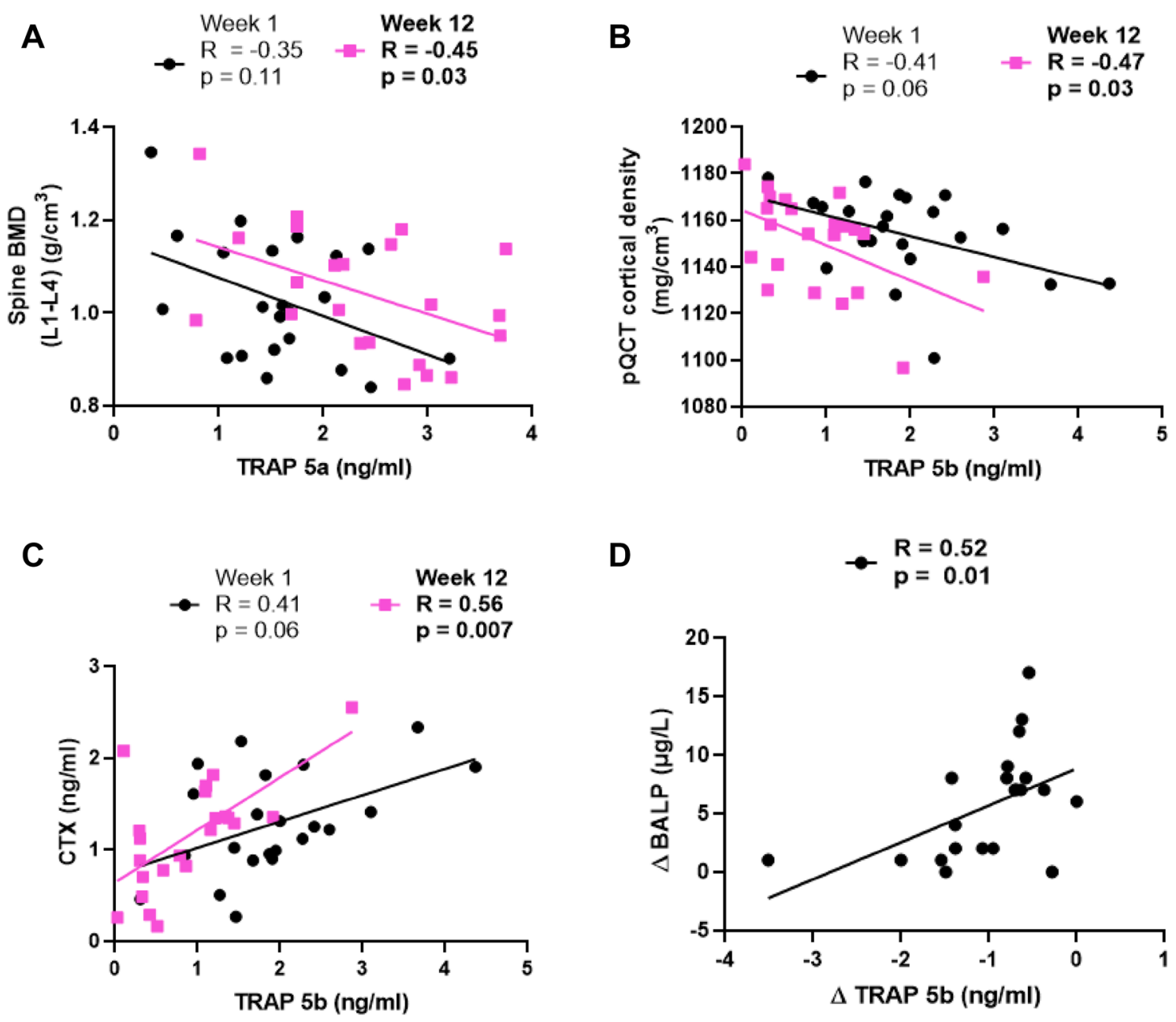

Fig. 3 Correlations of TRAP isoforms to bone mass and biochemical parameters. a Serum TRAP 5a protein vs spine BMD. b Serum TRAP 5b protein vs pQCT cortical bone density. c Serum TRAP 5b protein vs CTX. d Serum $\Delta$ TRAP $5 b$ protein vs $\Delta$ BALP. $N=22$ in all analysis

or pathological, i.e., from normal to obese weight gain [12]. Weight gain in AN versus obesity reflects different states with different components such as adipose inflammation and metabolic aberrations that could affect the involvement of TRAP 5a. On the other hand, the observed downregulation of TRAP $5 \mathrm{~b}$ is in accordance with weight restoration and increased bone mass after weight gain therapy in the AN group [6]. Thus, the increased bone mass is most likely due to a combination of increased bone formation, as reflected by the increase in bone anabolic parameters, i.e., levels of BALP induced by the 12-week therapy [6], as well as decreased bone resorption and lower numbers of osteoclasts, as reflected by decreased serum levels of TRAP $5 b$.

The observed changes of TRAP 5a and TRAP $5 \mathrm{~b}$ (in opposite directions) agree with that of total TRAP (i.e., the sum of TRAP $5 \mathrm{a}$ and $5 \mathrm{~b}$ was not significantly changed). The TRAP 5a/TRAP 5b ratio was also significantly altered with approximately a 4-fold increase). The abundance of TRAP $5 \mathrm{a}$, that is, 4 -fold more than TRAP $5 \mathrm{~b}$, has previously been reported in healthy individuals where TRAP 5a has been in the range of 4-8 $\mathrm{ng} / \mathrm{ml}[33,34]$, while other studies have reported TRAP $5 \mathrm{~b}$ levels in the range of $1-3 \mathrm{ng} / \mathrm{ml}[23$, 24]. Thus far, there are no studies that have investigated the ratio between TRAP $5 \mathrm{a}$ and $5 \mathrm{~b}$ directly in the same serum sample from humans. Previously, it has been reported that TRAP $5 \mathrm{a}$ is secreted by macrophages from adipose tissue [30]; thus, the observed inverse correlation between TRAP $5 \mathrm{a}$ and weight at baseline, but not at week 12 , could be due to exceptionally low amounts of adipose tissue and increased inflammation at the study start.

Interestingly, TRAP 5a was negatively associated with bone parameters such as lumbar spine BMD, which further implicate the involvement of TRAP 5a in bone regulation since it has been proposed to function as both positive and negative regulators of, e.g., osteoblasts [35]. However, TRAP 5a did not correlate to most of the bone parameters measured in this study. The role of TRAP 5a as a bone marker is unknown and this study is limited by a rather small 
number of participants; therefore, it is difficult to conclude the reason and implication for this. Future studies including larger cohorts are necessary to elucidate the possible role of TRAP 5a as a bone marker in patients with AN or other pathologies affecting bone.

TRAP $5 b$ was associated with bone parameters such as CTX, calcaneal BMD and BMC, as well as cortical and trabecular density, in accordance with previous studies [19], thus further demonstrating that serum TRAP $5 \mathrm{~b}$ is predominantly derived from bone tissue and reflects the number and activity of osteoclasts. The correlation of $\Delta$ TRAP $5 \mathrm{~b}$ to $\triangle \mathrm{pQCT}$ trabecular density is additionally consistent with more rapid turnover in trabecular compared to cortical bone. It is difficult to reason why TRAP $5 b$ is correlated to, e.g., calcaneal BMD but not spinal or total BMD. One reason might be the small number of participants and other that there are site-specific differences in osteoclast metabolism. As for TRAP 5a, future studies including larger cohorts are necessary to elucidate the precise role of TRAP $5 b$ as a bone marker in $\mathrm{AN}$ or other bone pathologies.

Additionally, this study further suggests that it is important to calculate the TRAP $5 \mathrm{a} / 5 \mathrm{~b}$ ratio. TRAP $5 \mathrm{a} / 5 \mathrm{~b}$ ratio correlated negatively to total BMC and calcaneal BMD/ BMC. This strengthens the idea that TRAP correlation to BMD and BMC in spine vs calcaneal bone might be a consequence of site-specific differences between spine and calcaneal bone since TRAP $5 \mathrm{a} / 5 \mathrm{~b}$ ratio correlates with calcaneal but not spine BMC and BMD at week 1. TRAP $5 \mathrm{a} / 5 \mathrm{~b}$ ratio also correlates to both cortical (positive) and trabecular (negative) density at week 1 implying that TRAP as a bone marker might not only be site specific between different bones entities but also site specific within a bone. Together, the increased number of bone parameters correlating to TRAP 5a/5b ratio compared to TRAP $5 \mathrm{~b}$ alone suggests that the TRAP $5 \mathrm{a} / 5 \mathrm{~b}$ ratio could be a more sensitive parameter for bone resorption than TRAP $5 \mathrm{~b}$ alone indicating that a low TRAP $5 \mathrm{a} / 5 \mathrm{~b}$ ratio could predict a pathological bone phenotype.

The observed delta values in serum TRAP 5a, between baseline and 12 weeks and TRAP $5 \mathrm{a} / 5 \mathrm{~b}$ ratio at week 1 , were correlated to changes in serum insulin indicating that TRAP $5 \mathrm{a}$ is involved in metabolic changes, which is in conjunction with previous reports $[33,36]$. However, the exact mechanism by which TRAP 5a responds to metabolic changes and insulin sensitivity/resistance remains to be elucidated. Finally, $\Delta$ decrease in TRAP $5 \mathrm{~b}$ was shown to be correlated to $\Delta$ increase in BALP, further suggesting that coupling between bone formation and bone resorption is restored during weight gain treatment of the AN cohort.

The rather small number of participants is a limitation, which makes our results difficult to generalize. However, this 12-week nutrition therapy for AN is highly staff-intensive (with 24-h surveillance), which made it difficult to include further AN patients. The lack of a control group is also a limitation; however, controls were not included because we found it unethical to recruit normalweight young women that would agree to a diet with the objective of gaining weight in a hospitalized environment for 12 weeks.

In conclusion, patients with $\mathrm{AN}$, who received the described intensive weight gain therapy and increased their BMI and body weight, demonstrated also changes, in opposite directions, for serum TRAP $5 \mathrm{a}$ and TRAP $5 \mathrm{~b}$ toward normal levels. The observed decrease for TRAP $5 \mathrm{~b}$ was linked to increased bone formation and decreased bone resorption, leading to improved bone mass. The increase for TRAP 5a seems to derive from overall systemic changes in bone as well as metabolic changes but is not directly correlated to expansion of adipose tissue. The combination of serum TRAP 5a and TRAP 5b, as well as the restoration of TRAP 5a/TRAP $5 b$ ratio, could be further indicative of reduced bone resorption and overall improved bone homeostasis after 12-week nutrition therapy. Future studies should aim to verify these results in larger cohorts of AN patients as well as other adipose tissue and bone pathologies to fully understand the role of TRAP isoforms as biomarkers.

Acknowledegments Open access funding provided by Karolinska Institute. We thank the participating adolescents for their enthusiasm and patience, and the staff at the Anorexia ward at the Queen Silvia Children's Hospital. We acknowledge the expert assistance of Anne Dohsé for the DXA measurements. The study was financed by grants from the Queen Silvia Children's Hospital Research Foundation, ALF Grants Region Östergötland, The Capio Foundation, The Samariten Foundation, The H.K.H Princess Lovisa's Foundation, The Sahlgrenska University Hospital and The Health \& Medical Care Committee of the Regional Executive Board Region Västra Götaland, the Swedish state under the agreement between the Swedish government and the county councils, the ALF-agreement (ALFGBG-716831) and from and the Swedish Research Council (VR) (K2015-99x-10363-23-4).

Data availability The datasets generated during the current study are available from Dr. Diana Swolin-Eide or Dr. Bojan Tubic on reasonable request.

\section{Compliance with ethical standards}

Conflict of interest The authors declare no conflict of interest for this investigation and take full responsibility for the manuscript.

Ethical approval All procedures performed in studies involving human participants were in accordance with the ethical standards of the local research ethics committee at Gothenburg University (720-11, date 2011-12-20) and with the 1964 Helsinki declaration and its later amendments or comparable ethical standards.

Informed consent Informed consent was obtained from all individual participants included in the study. 
Open Access This article is distributed under the terms of the Creative Commons Attribution 4.0 International License (http://creativeco mmons.org/licenses/by/4.0/), which permits unrestricted use, distribution, and reproduction in any medium, provided you give appropriate credit to the original author(s) and the source, provide a link to the Creative Commons license, and indicate if changes were made.

\section{References}

1. Wentz E, Gillberg IC, Anckarsater H, Gillberg C, Rastam M (2009) Adolescent-onset anorexia nervosa: 18-year outcome. Br J Psychiatry 194:168-174. https://doi.org/10.1192/bjp. bp.107.048686

2. Råstam M, Gillberg C, Garton M (1989) Anorexia nervosa in a Swedish urban region. A population-based study. Br J Psychiatry 155:642-646. https://doi.org/10.1192/BJP.155.5.642

3. Pettersson C, Tubic B, Svedlund A, Magnusson $\mathrm{P}$, Ellegård L, Swolin-Eide D, Forslund HB (2016) Description of an intensive nutrition therapy in hospitalized adolescents with anorexia nervosa. Eat Behav 21:172-178. https://doi.org/10.1016/j.eatbe h.2016.03.014

4. Gordon CM, Zemel BS, Wren TAL, Leonard MB, Bachrach LK, Rauch F, Gilsanz V, Rosen CJ, Winer KK (2017) The determinants of peak bone mass. J Pediatr 180:261-269. https://doi. org/10.1016/j.jpeds.2016.09.056

5. Miller K, Grinspoon S, Ciampa J, Hier J, Herzog D, Klibanski A (2005) Medical findings in outpatients with anorexia nervosa. Arch Intern Med 165:561-566. https://doi.org/10.1001/archi nte.165.5.561

6. Tubić B, Pettersson C, Svedlund A, Forslund H, Magnusson P, Swolin-Eide D (2016) Increased bone mineral content during rapid weight gain therapy in anorexia nervosa. Horm Metab Res 48:664-672. https://doi.org/10.1055/s-0042-115304

7. El Ghoch M, Gatti D, Calugi S, Viapiana O, Bazzani PV, Grave RD (2016) The association between weight gain/restoration and bone mineral density in adolescents with anorexia nervosa: a systematic review. Nutrients 8:1-16. https://doi.org/10.3390/nu812 0769

8. Rigotti N, Neer R, Skates S, Herzog D, Nussbaum S (2006) The clinical course of osteoporosis in anorexia nervosa. Obstet Gynecol Surv 46:638-639. https://doi.org/10.1097/00006254199109000-00023

9. Vestergaard P, Emborg C, Støving RK, Hagen C, Mosekilde L, Brixen K (2002) Fractures in patients with anorexia nervosa, bulimia nervosa, and other eating disorders-a nationwide register study. Int J Eat Disord 32:301-308. https://doi.org/10.1002/ eat. 10101

10. Lam WK, Eastlund DT, Li CY, Yam LT (1978) Biochemical properties of tartrate-resistant acid phosphatase in serum of adults and children. Clin Chem 24:1105-1108

11. Janckila AJ, Yam LT (2009) Biology and clinical significance of tartrate-resistant acid phosphatases: new perspectives on an old enzyme. Calcif Tissue Int 85:465-483. https://doi.org/10.1007/ s00223-009-9309-8

12. Patlaka C, Mira Pascual L, Paulie S, Henriksson A-F, Arner P, Lång P, Andersson G (2017) The adipokine tartrate resistant acid phosphatase $5 \mathrm{a}$ in serum correlates to adipose tissue expansion in obesity. Biomarkers 22:764-774. https://doi.org/10.1080/13547 50X.2017.1334155

13. Shih K-C, Janckila AJ, Lee W-J, Chou Y-C, Huang C-J, Kwok C-F, Ho L-T, Chao T-Y (2015) Effects of bariatric weight loss surgery on glucose metabolism, inflammatory cytokines, and serum tartrate-resistant acid phosphatase 5a in obese Chinese adults. Clin Chim Acta 30:197-202. https://doi.org/10.1016/j. cca.2015.11.004

14. Shih K-C, Janckila AJ, Kwok C-F, Ho L-T, Chou Y-C, Chao T-Y (2010) Effects of exercise on insulin sensitivity, inflammatory cytokines, and serum tartrate-resistant acid phosphatase $5 \mathrm{a}$ in obese Chinese male adolescents. Metabolism 59:144-151. https ://doi.org/10.1016/j.metabol.2009.06.035

15. Wu Y-Y, Janckila AJ, Slone SP, Perng W-C, Chao T-Y (2014) Tartrate-resistant acid phosphatase 5a in sarcoidosis: further evidence for a novel macrophage biomarker in chronic inflammation. J Formos Med Assoc 113:364-370. https://doi. org/10.1016/j.jfma.2012.07.033

16. Janckila AJ, Neustadt DH, Nakasato YR, Halleen JM, Hentunen T, Yam LT (2002) Serum tartrate-resistant acid phosphatase isoforms in rheumatoid arthritis. Clin Chim Acta 320:49-58

17. Luukkonen J, Pascual LM, Patlaka C, Lång P, Turunen S, Halleen J, Nousiainen T, Valkealahti M, Tuukkanen J, Andersson G, Lehenkari P (2017) Increased amount of phosphorylated proinflammatory osteopontin in rheumatoid arthritis synovia is associated to decreased tartrate-resistant acid phosphatase $5 \mathrm{~B} / 5 \mathrm{~A}$ ratio. PLoS ONE. https://doi.org/10.1371/journal.pone.01829 04

18. Halleen JM, Alatalo SL, Suominen H, Cheng S, Janckila AJ, Vaananen HK (2000) Tartrate-resistant acid phosphatase 5b: a novel serum marker of bone resorption. J Bone Miner Res 15:1337-1345

19. Halleen JM, Ylipahkala H, Alatalo SL, Janckila a J, Heikkinen JE, Suominen H, Cheng S, Väänänen HK (2002) Serum tartrateresistant acid phosphatase $5 \mathrm{~b}$, but not $5 \mathrm{a}$, correlates with other markers of bone turnover and bone mineral density. Calcif Tissue Int 71:20-5. https://doi.org/10.1007/s00223-001-2122-7

20. Takahashi K, Janckila AJ, Sun SZ, Lederer ED, Ray PC, Yam LT (2000) Electrophoretic study of tartrate-resistant acid phosphatase isoforms in endstage renal disease and rheumatoid arthritis. Clin Chim Acta 301:147-158

21. Morisawa T, Nakagomi A, Kohashi K, Kusama Y, Shimizu W (2017) Serum tartrate-resistant acid phosphatase-5b levels are associated with the severity and extent of coronary atherosclerosis in patients with coronary artery disease. J Atheroscler Thromb 24:9-16. https://doi.org/10.5551/jat.39339

22. Zenger S, He W, Ek-Rylander B, Vassiliou D, Wedin R, Bauer H, Andersson G (2011) Differential expression of tartrate-resistant acid phosphatase isoforms $5 \mathrm{a}$ and $5 \mathrm{~b}$ by tumor and stromal cells in human metastatic bone disease. Clin Exp Metastasis 28:65-73. https://doi.org/10.1007/s10585-010-9358-4

23. Galusca B, Zouch M, Germain N, Bossu C, Frere D, Lang F, Lafage-Proust MH, Thomas T, Vico L, Estour B (2008) Constitutional thinness: unusual human phenotype of low bone quality. J Clin Endocrinol Metab 93:110-117. https://doi.org/10.1210/ jc. $2007-1591$

24. Galusca B, Bossu C, Germain N, Kadem M, Frere D, LafageProust MH, Lang F, Estour B (2006) Age-related differences in hormonal and nutritional impact on lean anorexia nervosa bone turnover uncoupling. Osteoporos Int 17:888-896. https://doi. org/10.1007/s00198-005-0063-0

25. (2000) Diagnostic and Statistical Manual of Mental Disorders, 4th Edition, Text Revision (DSM-IV-TR), 4th ed. American Psychiatric Association, USA

26. Neu CM, Manz F, Rauch F, Merkel A, Schoenau E (2001) Bone densities and bone size at the distal radius in healthy children and adolescents: a study using peripheral quantitative computed tomography. Bone 28:227-232

27. Soderpalm AC, Kullenberg R, Albertsson-Wikland K, SwolinEide D (2005) Pediatric reference data for bone mineral density in the calcaneus for healthy children 2,4 , and 7 years of age by 
dual-energy X-ray absorptiometry and laser. J Clin Densitom $8: 305-313$

28. Tubić B, Pettersson C, Svedlund A, Forslund H, Magnusson P, Swolin-Eide D (2016) Increased bone mineral content during rapid weight gain therapy in anorexia nervosa. Horm Metab Res 48:664-672. https://doi.org/10.1055/s-0042-115304

29. Svedlund A, Pettersson C, Tubic B, Magnusson P, Swolin-Eide D (2017) Vitamin D status in young Swedish women with anorexia nervosa during intensive weight gain therapy. Eur J Nutr 56:2061-2067. https://doi.org/10.1007/s00394-016-1244-7

30. Lang P, Zakaroff-Girard A, Wahlen K, Andersson J, Olsson T, Bambace C, Jocken J, Bouloumie A, Andersson G, Arner P (2011) Expression and secretion of the novel adipokine tartrate-resistant acid phosphatase from adipose tissues of obese and lean women. Int J Obes 35:1502-1510. https://doi.org/10.1038/ijo.2011.17

31. Patlaka C, Mai HA, Lång P, Andersson G (2014) The growth factor-like adipokine tartrate-resistant acid phosphatase $5 \mathrm{a}$ interacts with the rod G3 domain of adipocyte-produced nidogen-2. Biochem Biophys Res Commun 454:446-452. https://doi. org/10.1016/j.bbrc.2014.10.112

32. Chao TY, Lee SH, Chen MM, Neustadt DH, Chaudhry UA, Yam LT, Janckila AJ (2005) Development of immunoassays for serum tartrate-resistant acid phosphatase isoform 5a. Clin Chim Acta 359:132-140. https://doi.org/10.1016/j.cccn.2005.03.039
33. Huang Y-J, Huang T-W, Chao T-Y, Sun Y-S, Chen S-J, Chu D-M, Chen W-L, Wu L-W (2017) Elevated serum tartrate-resistant acid phosphatase isoform 5a levels in metabolic syndrome. Oncotarget 5:78144-78152. https://doi.org/10.18632/oncotarget.17839

34. Janckila AJ, Lin H-F, Wu Y-Y, Ku C-H, Yang S-P, Lin W-S, Lee S-H, Yam LT, Chao T-Y (2011) Serum tartrate-resistant acid phosphatase isoform 5a (TRACP5a) as a potential risk marker in cardiovascular disease. Clin Chim Acta 412:963-969. https://doi. org/10.1016/j.cca.2011.01.035

35. Hayman A (2008) Tartrate-resistant acid phosphatase (TRAP) and the osteoclast/immune cell dichotomy. Autoimmunity 41:218223. https://doi.org/10.1080/08916930701694667

36. Lång $\mathrm{P}$, van Harmelen V, Rydén M, Kaaman M, Parini P, Carneheim C, Cassady AI, Hume D, Andersson G, Arner P (2008) Monomeric tartrate resistant acid phosphatase induces insulin sensitive obesity. PLoS One 3:e1713. https://doi.org/10.1371/journ al.pone. 0001713

Publisher's Note Springer Nature remains neutral with regard to jurisdictional claims in published maps and institutional affiliations.

\section{Affiliations}

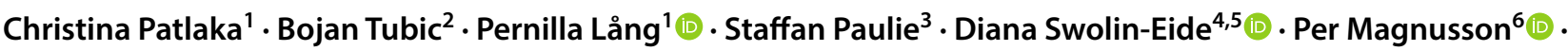 Göran Andersson ${ }^{1}$}

Christina Patlaka

Christina.Patlaka@ki.se

Bojan Tubic

bojan.tubic@gu.se

Staffan Paulie

Staffan.Paulie@mabtech.com

Diana Swolin-Eide

diana.swolin-eide@vgregion.se

Per Magnusson

Per.Magnusson@ regionostergotland.se

Göran Andersson

Goran.Andersson@ki.se

1 Division of Pathology, Department of Laboratory Medicine, Karolinska Institutet, Huddinge, Sweden
2 Department of Orthopaedics, Institute of Clinical Sciences, Sahlgrenska University Hospital, Sahlgrenska Academy, University of Gothenburg, Göteborg, Sweden

3 Mabtech AB, Nacka Strand, Sweden

4 Department of Pediatrics, Institute of Clinical Sciences, Sahlgrenska Academy, University of Gothenburg, Gothenburg, Sweden

5 The Queen Silvia Children's Hospital, Sahlgrenska University Hospital, Gothenburg, Sweden

6 Department of Clinical Chemistry, and Department of Clinical and Experimental Medicine, Linköping University, Linköping, Sweden 